\title{
UMA UTOPIA OITOCENTISTA: IGUALDADE, TRABALHO E ESTADO EM UMA SOCIEDADE IMAGINADA POR EDWARD BELLAMY
}

\author{
AN OITOCENTIST UTOPIA: EQUALITY, LABOR AND STATE IN A \\ SOCIETY IMAGINATED BY EDWARD BELLAMY
}

José D’Assunção Barros ${ }^{1}$

RESUMO

\begin{abstract}
Este artigo examina a literatura utópica do século XIX, abordando mais diretamente, e em maior profundidade, a sociedade imaginária idealizada por Edward Bellamy no romance Olhando para Trás (1888). Esta análise mais específica é precedida por uma breve introdução à literatura utópica desde o século XVI - recuperando comparativamente proposições de autores como Thomas Morus, Campanella, Francis Bacon, Fourier, Saint-Simon, e Robert Owen -, além de uma discussão teórica sobre os modelos de distribuição da igualdade, neste caso considerando as reflexões de Norberto Bobbio e Amartya Sen sobre este tema. O romance de Bellamy é abordado em seu contexto, e justifica-se por envolver uma ponte entre literatura e sociedade, particularmente considerando que esta obra despertou grande interesse de leitores da época e mesmo a motivação para a realização de experiências utópicas específicas.
\end{abstract}

Palavras chave: Literatura utópica. Sociedades imaginárias. Igualdade. Bellamy.

ABSTRACT

This article attempts to examine the utopian literature of the nineteenth century, approaching more directly, in more deeply, the imaginary society devised by Edward Bellamy, in the novel Looking Backward (1888). These more specific analyse is preceded by a brief introduction to utopian literature since the XVI century - recovering comparatively propositions of authors such as Thomas More, Campanella, Francis Bacon, Fourier, Saint-Simon, and Robert Owen - , besides a theoric discussion about the models of equality distribution, in this case considering the reflections of Norberto Bobbio and Amartya Sen on this topic. The novel of Bellamy is addressed in their historical context, and is justified because it concerns a bridge between

${ }_{1}^{1}$ Universidade Federal Rural do Rio de Janeiro - professor colaborador do Programa de Pós-Graduação em História Comparada da Universidade Federal do Rio de Janeiro. Doutor em História pela Universidade Federal Fluminense. 
literature and society, since this work has aroused great interest of readers of the time and even inspired a motivation for carrying out specific utopian experiments.

Keyword: Utopist literature. Imaginary societies. Equality. Bellamy.

A noção de igualdade e o empenho em com ela conciliar a constatação sobre as diferenças humanas tem sido um sonho antigo, tanto entre aqueles que se empenharam na construção e reconstrução de sociedades reais, como entre aqueles que idealizaram sociedades imaginárias. Neste artigo, nosso objetivo será o de refletir sobre um autor oitocentista que idealizou, em um romance, uma sociedade imaginária no futuro dos Estados Unidos da América, e que, com o sucesso de sua idealização entre leitores que recepcionaram seu livro, organizou clubes visando a futura possibilidade de concretizar um encaminhamento para o seu sonho utópico. Trataremos de Edward Bellamy e de sua oba "Olhando para trás" (Looking Backward, 1888)1. Trata-se mais especificamente de verificar como este autor lidou com as idéias de igualdade, desigualdade, diferença, como pensou um sistema social e um espaço de convivência para a sociedade por ele idealizada, como equacionou a relação entre produção e trabalho, entre estas duas e o ócio, e como conciliou governo e liberdade. Questões como estas - as quais sempre aparecem em todas as utopias imaginadas até hoje, e que adquirem uma especificidade no romance utópico de Edward Bellamy - tornam-se importantes nesta produção literária porque são questões reais, concretas, presentes nas próprias sociedades em que vivemos, e no interior das quais é possível imaginar utopias e sociedades imaginárias.

Antes de chegarmos a uma análise da sociedade imaginada por Bellamy, todavia, será oportuno mobilizar um sistema conceitual que permitirá estabelecer um liame comparativo para as análises. Oportunamente, partiremos de uma reflexão sobre os diversos âmbitos diante dos quais se pode delimitar os diversos tipos de igualdade. Por ora, será importante refletirmos preliminarmente sobre as características do gênero literário utópico, definindo-o como uma subcategoria de textos que seriam comparáveis. Tal reflexão será elaborada no próximo item.

\section{O gênero literário utópico}

A designação "utopia" traz consigo uma história extensa e complexa, a qual remonta à primeirautilização do termo porThomas Morus(1516)e sebeneficia de múltiplas ressignificações posteriores, sejam estas valorativas ou pejorativas ${ }^{2}$. Para Morus, escritor renascentista inglês que teve o mérito de ser o introdutor da palavra no cenário literário e político, a expressão remetia simultaneamente, por homofonia, ao "não-lugar" de uma sociedade situada fora do

${ }^{1} \mathrm{O}$ título completo da obra em inglês é Looking Backward: 2000-1887, o que expressa a situação de um personagem que vai para o seu futuro (2000) e por isso tem a possibilidade de examinar comparativamente este futuro e também o seu próprio presente, agora tornado passado. A obra, como sugere o título, foi escrita em 1887, mas somente publicada no ano seguinte. Em português, em uma edição da Editora Record de 1960, recebeu o título de Daqui a cem anos: revendo o futuro. No presente texto, vamos nos referir ao título deste livro de Edward Bellamy simplesmente como "Olhando para Trás".

${ }^{2}$ Um estudo desta história, para a língua francesa, foi realizado por H. G. Funke (1988). Uma coletânea com artigos sobre a definição de utopia foi organizada por Neusüss (1971). Ver ainda Suvin (1977). 
nosso espaço e da nossa linha de tempo (ou-topia) e ao "lugar da felicidade" consolidado por uma sociedade perfeita (eu-topia). Essa dupla superposição de sentidos - o "não-lugar geográfico" sobre o qual se estabelece um "país imaginário", e o "lugar da felicidade" no qual se redesenha uma sociedade perfeita- estará presente em diversas das realizações literárias da imaginação utópica. Empregaremos a palavra com esta dupla potencialidade, particularmente porque estes dois sentidos podem ser sintonizados com relação à perspectiva utópica introduzida por Olhando para Trás, de Edward Bellamy, em cuja análise nos deteremos mais adiante. Afinal, como veremos oportunamente, a utopia literária elaborada por Bellamy em Olhando para Trás (1888) gerou posteriormente círculos de bellamistas que discutiram a possibilidade de fundar comunidades ${ }^{3}$.

Alguns aspectos são recorrentes em muitas das criações literárias que podemos classificar no interior do 'gênero utópico'. Há inicialmente o empenho em descrever uma sociedade estruturalmente exequível e passível de ser percebida pelo leitor como dotada de veridicidade, ao contrário das criações literárias francamente fantasiosas que podem ser exemplificadas com as fantasias de inesgotável abundância que espontaneamente brota do solo, sem nenhum trabalho ou sistema produtivo, à maneira da Cocanha medieval. Queremos dizer com isso que as utopias necessariamente desenvolvem uma lógica capaz de ser compreendida e aceita pelos seus leitores, mesmo com todo o seu estranhamento.

Além disso, as utopias literárias (ou o 'gênero utópico') são muito habitualmente assinaladas pelo signo da viagem. O personagem central de Thomas Morus viajou para a sua Utopia, ainda que esta estivesse situada em um não-lugar, e os personagens centrais da Cidade do Sol, de Campanella, da Nova Atlântida, de Francis Bacon, ou da Icária de Cabet, também chegaram ao seu destino utópico a partir de uma viagem. De igual maneira, Edward Bellamy (1850-1898), em seu romance utópico Olhando para Trás (1888), faz com que seu personagem central atinja a sua sociedade utópica por meio de uma viagem, só que realizada no tempo. Em todos estes casos, a viagem mostra-se típica das realizações literárias enquadráveis no gênero utópico, pois isto permite contrapor um antigo mundo a ser radicalmente criticado a outro, ao qual se chega através de uma viagem, seja esta proporcionada por um deslocamento no espaço, no tempo, ou no mundo dos sonhos. Evocamos este aspecto apenas como mais um sintoma do caldo de intertextualidades que recobre a história do 'gênero utópico'.

Poderíamos acrescentar, ainda como traço característico do gênero utópico, a tendência a um determinado estilo narrativo, no qual a narração se subordina à descrição da cidade ideal, principal objetivo dos romances utópicos. Frequentemente, ademais, essa cidade ideal fundase em uma "perfeição institucional" que é minuciosamente descrita pelo Cioranescu (1972, p.53) ${ }^{4}$ o qual se empenha em oferecer, através da sua obra, uma esquematização da realidade

${ }^{3}$ Se é impossível chegar a uma definição consensual de utopia, ou mesmo para a categoria literária do 'gênero utópico', que já discutiremos, podemos reconhecer que existe uma série de definições no tempo, as quais responde às especificidades dos vários autores e as demandas de sua época. Para um panorama de definições de utopia, ver Levitas (1990) e Quarta (2006).

${ }^{4}$ Para uma discussão sobre a perfectibilidade utópica, ver Racault (2009, p.32). 
literária por ele construída. Por isso, no modelo mais habitual que subjaz ao gênero utópico, são os tópicos relacionados aos diversos problemas enfrentados pelo desafio utópico de realizar e organizar uma sociedade ideal que conduzem o fio narrativo, aqui transformado em um itinerário para que sejam percorridos os problemas em pauta ${ }^{5}$. Esse modelo calcado no itinerário didático, ademais, junta-se a outra característica essencial presente no gênero utópico: o espelhamento - explícito ou implícito - da utopia em relação à civilização que se quer criticar.

Antes de chegar a esta análise mais aproximativa sobre a utopia literária proposta por Bellamy, e com vistas a melhor preparar o problema específico que examinaremos na sociedade por ele imaginada, será oportuno mobilizar um sistema conceitual que permita estabelecer um liame comparativo para as análises a serem empreendidas. Partiremos de uma reflexão sobre os diversos âmbitos diante dos quais se podem delimitar os diversos tipos de igualdade.

\section{Duas perguntas fundamentais sobre a Igualdade}

Uma boa baliza de sistematização para a compreensão dos sistemas que discutem a igualdade foi proposta por Norberto Bobbio na sua Teoria Geral da Política. Para o cientista político italiano, todo esforço no sentido de refletir sistematicamente sobre a igualdade deve partir de duas perguntas fundamentais. Quando se começa a falar em igualdade, uma primeira pergunta é: "igualdade entre quem?". Concomitantemente, pergunta-se de imediato: "igualdade em relação ao que?" (BOBBIO, 2000, p. 298-299). Além disso, é preciso considerar que a indagação "igualdade de que" pode implicar vários desdobramentos que, para utilizar uma expressão de Amartya Sem (2001), poderemos chamar aqui de variáveis focais. Cada variável focal define um espaço ao qual se refere a igualdade proposta ou pretendida. Pode ser proposta a Igualdade de Algo como a escolha de representantes, as oportunidades de trabalho, de instrução, e, no limite, a Igualdade de Tudo. Em seguida, deve-se ter em vista que as perguntas primordiais unidas ("igualdade entre quem" e "igualdade de que") podem se ramificar em quatro possibilidades de respostas que, segundo Bobbio, seriam as seguintes: Igualdade de Alguns em relação a Algo; Igualdade de Alguns em Tudo; Igualdade de Todos em alguma coisa; Igualdade de Todos em Tudo. Será possível esquematizar este plano de categorias:

\footnotetext{
${ }^{5}$ Michel Racault, um dos estudiosos mais conceituados das utopias, chega a afirmar como característica do gênero utópico a intenção de se aproximar da ideia de que o narrador da viagem utópica elabora uma espécie de "reconstrução antropológica total", comportando "instituições, uma estrutura social, uma economia, uma religião, uma língua, etc, sendo cada elemento correlacionado a todos os outros" (RACAULT, 2009, p.31). A ideia de que é característica obrigatória da utopia a globalidade, extensível para todos os aspectos da vida humana, é também sustentada por Luigi Firpo (2005, p.229).
} 
Figura 1- Duas perguntas entrelaçadas e quatro respostas

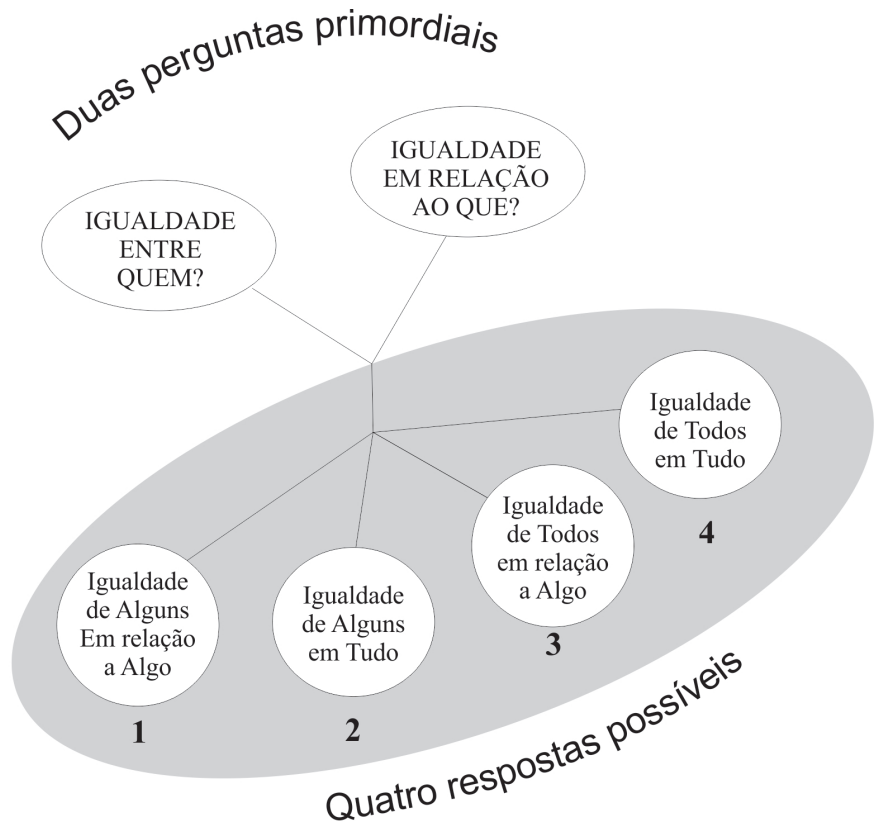

Fonte: Esquema elaborado pelo autor

Os exemplos enquadráveis em cada um destes casos podem ser encontrados fartamente na História das ideias e na história de fato. Vamos entender esta última como a história que corresponde ao conjunto de processos e acontecimentos que se desenvolveram e aconteceram efetivamente, no mundo humano vivido, e a primeira como o conjunto de pensamentos e concepções que daí emerge e interage com a história de fato de muitas maneiras, incluindo as produções e perspectivas derivadas desta imaginação utópica onde a crítica do presente e a imaginação do futuro se entrelaçam através deste gênero que é a literatura utópica.

Voltemos ao nosso esquema para examinar a primeira possibilidade (Igualdade de Alguns em relação a Algo). Tal como faz notar Bobbio, esse é o lugar comum de qualquer lei ou regulamentação. Toda Lei refere-se a sujeitos ou pacientes que possuem algo em comum que os enquadre na situação específica de que trata a Lei - e que desta forma correspondem apenas a um subconjunto do universo maior de cidadãos. Ao mesmo tempo, a Lei estabelece direitos ou penalidades relativamente a algum aspecto. Resumindo a questão, uma lei refere-se a indivíduos específicos com relação a um problema igualmente específico.

A resposta número 2 , bem como as demais respostas, já nos conduz à aventura humana do pensamento político. "Igualdade de Alguns em Tudo" era o que propunha Platão em República. Platão era crítico do modelo político de sua própria pólis - a Atenas clássica que se transformara em uma democracia plena, incluindo amplos direitos políticos para a parte mais miserável da população (conservando, entretanto, a exclusão dos escravos, dos estrangeiros e, em nível à parte, das mulheres). Entre os utopistas do século XIX - dentre os quais Edward Bellamy 
- veremos mostrar-se em vigor a proposta número 4: "igualdade de todos em tudo". Como viabilizar um tal sonho de igualitarismo? Veremos a seguir, como Edward Bellamy pensou esta questão e a expressou na sociedade futurista imaginária que emerge das páginas de seu romance Olhando para Trás. Antes, porém, será útil refletir sobre a sutil distinção que se pode fazer entre os modelos igualitários e os modelos igualitaristas.

\section{Igualitarismos}

Dentro do esquema proposto no primeiro item deste artigo, a resposta número 4 ("Igualdade de Todos em Tudo") conduz-nos às utopias e propostas igualitaristas. Não haverá possibilidade de examinar todos os imaginários igualitaristas nos limites deste artigo, mas pode-se de passagem dizer que as duas respostas imediatamente precedentes ("Igualdade de Alguns em Tudo" e "Igualdade de Todos em Algo") correspondem, cada qual à sua maneira, a padrões igualitários de algum tipo. A República de Platão - uma "Igualdade de Alguns em Tudo" - é uma utopia igualitária dentro dos limites a que se propõe: uma utopia com exclusão social daqueles que estão fora destes limites, e com clivagens sociais e funcionais específicas. Podese ainda dizer que mesmo o modelo proposto por John Locke e outros autores dos séculos XVII e XVIII que sinalizam para uma perspectiva liberal circula também dentro de uma proposta igualitária ("Igualdade de Todos em alguns aspectos"). Quem negará que a Declaração dos Direitos do Homem é um empolgante documento igualitário nos artigos que descrevem os direitos inalienáveis dos seres humanos? Amplamente, as democracias liberais amparam-se no imaginário da igualdade, mesmo que a sua base capitalista sustente-se amplamente na desigualdade.

Esses dois modelos - república platônica e democracia liberal - desenvolvem-se dentro dos limites igualitários. Mas o âmbito que sustenta diversas das utopias oitocentistas - entre as quais a sociedade criada literariamente por Edward Bellamy - refere-se ao igualitarismo. Há uma sutil distinção, será desde já oportuno assinalar, entre "igualitário" e "igualitarista". O igualitarismo propõe a plenitude da igualdade nos dois termos da equação: "Igualdade para Todos em Tudo (ou quase tudo)". Agora, sujeito e objeto do processo de equalização são expandidos tanto quanto possível. Em um dos limites, o sujeito da igualdade tende à unidade absoluta e desaparecem as classes sociais; no outro limite, o objeto da igualdade estende-se a todas as condições de vida, e sintomaticamente pode desaparecer a propriedade privada. Não é preciso que sejam atingidos esses limites mais extremos para que já seja pertinente falar em igualitarismo, mas de alguma maneira deveremos estar mais próximos a eles. Conforme veremos adiante, diversas obras da literatura utópica, e diversos projetos políticos que visam o estabelecimento de comunidades ou sociedades que visam a redução radical das desigualdades, apresentam propostas igualitaristas. Antes de chegarmos a esta questão, entretanto, será oportuno compreendermos o que seria, mais propriamente, a imaginação utópica. 


\section{Breve apreciação histórica da imaginação utópica}

Para entender os diversos modelos e matrizes igualitaristas, podemos retomar sumariamente a sua história. À parte as experiências mais limitadas do comunismo cristão primitivo, as utopias e os modelos políticos igualitaristas começam a se consolidar na modernidade. Um marco teórico particularmente importante é seguramente a Conspiração dos Iguais de Babeuf, texto escrito por Filippo Buonarroti em 1828. Por outro lado, as utopias igualitárias já haviam começado a aparecer na literatura desde o Humanismo Renascentista, particularmente com a Utopia de Thomas Morus (1478-1535) e a Cidade do Sol de Tomaso Campanella (1568-1639).

Associaremos a uma matriz comum, que denominaremos "matriz Morus", essas utopias igualitárias que prevêem um mundo habitado por seres sábios ou especiais - e que, portanto, estão prontos para uma vida tão isenta de tensões quanto possível (uma vida que, a bem da verdade, não pode ocorrer efetivamente senão fora deste mundo). É assim que a Utopia de Thomas Morus, descrita na obra de mesmo nome que foi publicada em 1516, apresenta-se como uma sociedade imaginária e idealizada na qual não existe a propriedade privada e se verifica uma absoluta comunidade de bens e a propriedade coletiva da terra, com ausência de antagonismos entre a cidade e o campo - traço utópico através do qual Morus encaminhava uma crítica à Inglaterra de sua época. De igual maneira, não existe trabalho assalariado, nem gastos supérfluos ou luxos excessivos e desnecessários, desempenhando o Estado o papel de órgão administrador da produção. Historicamente localizada, esta obra da imaginação utópica renascentista constitui simultaneamente uma crítica à sociedade feudal e à Inglaterra contemporânea a Thomas Morus. Tem o valor pioneiro de ter sido a primeira idealização de uma sociedade com comunidade de bens.

A organização política é democrática, com eleição direta dos magistrados até chegar à autoridade máxima exercida por um Príncipe. Mas é interessante observar o sistema fortemente autoritário previsto para evitar que haja conspirações, conluios e manipulações de opinião. Qualquer reunião política fora do Senado e das Assembléias Populares, onde e quando esteja prevista a discussão e votação periódica das leis, é punida com a morte. Existem instituições permanentes cuja função é impedir que os governantes conspirem contra a liberdade ou exerçam qualquer forma de tirania. Por outro lado, à parte esse regime autoritário de exceção face às situações que ameacem o funcionamento democrático, a Utopia é o lugar privilegiado da liberdade de pensamento. Morus constrói aqui um verdadeiro paraíso de tolerância religiosa, já que os habitantes da Utopia professam os mais variados credos sem que quaisquer deles entrem em colisão.

A matriz igualitarista apresentada por Thomas Morus pressupõe a existência de homens sábios - prontos para um mundo de Liberdade e Igualdade, sem anseios egoístas de qualquer espécie. Um mundo de homens que não existem, poderíamos acrescentar. Mundo também sem história, pois o autor não apresenta nenhuma proposta de como teria sido possível chegar 
a este estado de perfeição política a partir de um mundo antes habitado por seres humanos comuns, ainda por se preparar para a igualdade, envolvidos em tensões sociais de todos os tipos e acalentando os interesses egoístas que surgem espontaneamente em uma sociedade competitiva. Ao se negar a examinar a passagem do mundo imperfeito ao mundo utópico, Morus também contorna a questão de apresentar um programa de revolução ou de transformação social. Condena seu mundo perfeito a um espaço imaginário, a um "não-lugar" proibido aos homens que estão mergulhados na história, e que precisam construir a sociedade em que irão viver com seus tateamentos e hesitações, suas imperfeições e revoluções.

Outras proposições utópicas que se aproximam do modelo proposta por Thomas Morus começam a aflorar com o humanismo Renascentista. Logo aparece a Cidade do Sol de Campanella (1568-1639) e A Nova Atlântida de Francis Bacon (1561-1626). Essas proposições utópicas são sustentadas ou pela ideia de que todos os seres que as habitam estão preparados para a felicidade, para a igualdade e para a liberdade - um pouco passando ao largo de colisões de situações e de interesses que podem ocorrer nas experiências reais - ou então aparece a ideia de que existe uma elite de sábios respeitados incondicionalmente por todos, e que por isso conseguem resolver todos os problemas sociais apontando infalivelmente a melhor solução. Nessa última variedade entramos no âmbito da pequena elite de governantes perfeitos, que com a sua presença e orientação utopizam todo o ambiente à sua volta. Esta clivagem entre uma pequena elite de governantes e a sociedade em favor da qual eles atuam, com autoritarismo mas também com sacrifício pessoal, é uma característica destes modelos utópicos, a qual os faz se distinguirem em relação ao modelo que analisaremos mais adiante (a utopia de Edward Bellamy).

A Cidade do Sol (1602), de Tomaso Campanella, por exemplo, além de se inspirar na Utopia de Morus, seu modelo imediato, mostra-se discretamente temperada com elementos oriundos da República de Platão. O que faz da Cidade do Sol uma utopia igualitarista é, sobretudo, o fato de que os bens são colocados em comum. Inexiste a propriedade e verifica-se uma educação igualitária. O igualitarismo transparece na própria indumentária, pois todos vestem roupas iguais. Destarte, o igualitarismo quebra-se um pouco quando entra em cena a questão do masculino e feminino. De fato, os dois sexos são tratados diferentemente - senão com desigualdade, pelo menos com diferenças bastante claras que já começam a certo estágio da educação ministrada às crianças. Por outro lado, também matizando o igualitarismo pleno, a Cidade do Sol prevê critérios de distribuição fundados no mérito.

O detalhe que nos interessa é que esta utopia também se ampara na orientação e governo provenientes de um grupo destacado de sábios - um grande conselho de magistrados em forma piramidal, que tem no seu cume quatro sábios maiores, um deles desempenhando o papel de autoridade máxima. O Hoh, palavra que significaria "O Metafísico", é este sábio extremo que se situa no cimo do conselho piramidal de sábios. A ele estão ligados os outros três sábios: "Potência", "Amor" e "Sapiência" - cada qual reunindo setores importantes da vida social e dos campos humanos de pensamento e ação. Assim, o sábio "Potência" é o responsável final 
por tudo o que se relaciona à Paz e a Guerra; o sábio "Amor" rege tudo o que se relaciona com alimentação, vestuário e associação amorosa; e o sábio "Sapiência” rege as artes, as ciências e a instrução. A pirâmide da sabedoria estende-se para mais além. A cada um destes três sábios liga-se um certo número de magistrados. Por exemplo, o ministro "Sapiência" rege um círculo imediato de onze magistrados (Astrólogo, Cosmógrafo, Geômetra, Historiador, Poeta, Lógico, Retórico, Gramático, Médico, Fisiólogo, Moralista). Desse modo é formada a pirâmide de sábios que, destacadamente, rege a vida dos Iguais que habitam a Cidade do Sol. Embora os sábios sejam em última instância oriundos do próprio corpo de cidadãos, não deixa de se formar aqui aquela sociedade igualitária que precisa ter o seu sucesso assegurado pela orientação precisa de um corpo à parte - uma espécie de órgão especial dentro do próprio corpo cuidando para que tudo ocorra a contento e o organismo social se desenvolva.

Outro exemplar utópico renascentista é Nova Atlântida de Francis Bacon, obra postumamente publicada em 1627. A Atlântida imaginária proposta por Bacon opõe-se à Atlântida que Platão havia descrito na República. A comunidade utópica inventada por Bacon também tem o seu bem estar assegurado por um grupo de sábios que habita a Casa de Salomão - uma instituição científica cuja função é descobrir permanentemente meios de facilitar a vida em geral, bem como de orientar a vida dos cidadãos com vistas a lhes assegurar a felicidade. Sobretudo, é um corpo de cientistas, que trabalha incessantemente pela ampliação do conhecimento em todos os sentidos. Essa instituição científica é o verdadeiro coração da utopia proposta por Bacon, ligando-se aos centros agrícolas, aos centros de saúde, aos centros de produção de energia, e assim por diante. Os sábios são, neste caso, trabalhadores incansáveis que se dedicam a verter seu talento científico em benefício da comunidade inteira, a quem só resta usufruir um mundo de liberdade e igualdade perfeitamente harmonizado pela ciência e sabedoria. Um detalhe relevante é que a Nova Atlântida de Bacon já possui uma história. A Utopia de Thomas Morus e Cidade do Sol de Campanella são não apenas apresentadas como "não-lugares" (u-topias), mas também como realidades fora do tempo - uma vez que não se diz como se chegou a elas. Já $\mathrm{A}$ Nova Atlântida de Bacon tem uma origem: ela é fundada 900 anos antes do relato por um grande sábio altruísta que vem de fora. A utopia proposta por Bacon, desta forma, é implantada por um gesto magnânimo - ela não é gerada por um processo revolucionário, ou sequer por um processo de reformas graduais.

No século XIX, surgem propostas utópicas que, de certo modo, constituem variações mais modernas da utopia mórica, notando-se que, em geral, elas são acrescidas de uma intenção de se ver um dia concretizada, mesmo que ao final da tentativa não venham a encontrar sucesso. Em comum com o modelo igualitarista anterior, um rigoroso planejamento, imposto de cima. A primeira referência são as ideias de Charles Fourier (1772-1837). Já escrevendo de um mundo mais avançado em termos industriais, e que assistira aos recuos da Revolução Francesa, Fourier pretendia erigir o seu sonho de uma sociedade justa e igualitarista sob a complacência de 'capitalistas esclarecidos' sintonizados com as ideias liberais. O grande fundador, por outro 
lado, seria ele mesmo - portanto não mais um herói imaginário, mas um fundador histórico. Sabe-se, não obstante, que Fourier não logrou obter sucesso efetivo na implantação do seu projeto.

As Falanges propostas por Fourier seriam correspondentes a pequenas unidades sociais com populações de cerca de 1500 habitantes, e cada uma possuiria um edifício comum chamado Falanstério onde todos viveriam harmoniosamente ${ }^{6}$. Apesar de um cálculo relativo ao emparelhamento numérico de homens e mulheres, a ideia era que a vida no falanstério levaria espontaneamente à dissolução de formações sociais rudimentares como a célula familiar monogâmica e restrita. Para isso, o falanstério teria muitos espaços de socialização, inclusive as refeições, que seriam coletivas. Além disso, Fourier era um crítico visceral do casamento monogâmico. O comportamento tendente à multiplicação de contatos amorosos era por ele chamado de "angélico", e nos falanstérios deveria se aliar a um comportamento hedonista, no qual todos buscariam o máximo de prazer (o que já vimos na Utopia de Thomas Morus). 0 dinheiro e a propriedade privada, por exemplo, não seriam suprimidos - apesar de que, na vida "societária" e saudável do Falanstério, purificada dos padrões de egoísmo e individualismo que até então haviam caracterizado a sociedade dita "civilizada", nem o dinheiro nem a propriedade teriam quaisquer efeitos danosos e produtores de opressão econômica.

Por outro lado, como modelo de redistribuição da riqueza, previa-se que esta seria orientada de acordo com a qualidade do trabalho produzido por cada um - o que justificaria as diferenças em termos justos. Bem estabelecido, não seria uma remuneração privilegiando propriamente tipos diferentes de trabalho, mas sim a eficiência e o benefício real que os grupos profissionais estivessem produzindo para a comunidade. Quanto menos doentes tivesse um falanstério, mais os médicos deste falanstério seriam bem remunerados; quanto menos problemas estruturais ou de manutenção afligissem o Edifício, mais ganhariam os engenheiros e técnicos; quanto mais deliciosa e nutritiva fosse a alimentação, mais ganhariam os cozinheiros ou os que naquele mês tivessem se dedicado às atividades alimentícias. Desta forma, cada grupo funcional faria um esforço coletivo para elevar o padrão dos resultados de seu trabalho e, desta forma, os seus próprios ganhos.

Já o industrial Robert Owen(1771-1858) tentou ele mesmo implantar a sua sociedade reformada, investindo seus próprios recursos em colônias cooperativas nas quais a propriedade privada seria extinta. Ele já vinha obtendo algum sucesso em sua atividade industrial - organizando suas fábricas de maneira surpreendentemente humana e com grande justiça social, sem que isto prejudicasse o progresso capitalista de seus empreendimentos. Contudo, as tentativas de concretização do seu projeto realmente igualitarista fracassaram, em parte porque esse projeto sofreu muitas resistências da aristocracia inglesa de sua época.

\footnotetext{
${ }^{6} \mathrm{Em}$ uma obra chamada A Teoria dos quatro movimentos (1808), Fourier havia chegado à curiosa conclusão de que o falanstério deveria abrigar uma população de 1620 pessoas (810 de cada sexo). Fourier chegou ao seu número de 1620 a partir da teoria que desenvolvera dos Quatro Movimentos, segundo a qual os seres humanos seriam impulsionados por treze paixões especificadas. A população do inicial do Falanstério devia ser calculada de modo que todos na comunidade tivessem a oportunidade de encontrar outros com características complementares à sua.
} 
Por fim, como último exemplo, também era uma sociedade governada por um conselho de sábios e artistas a que havia proposto o conde Claude-Henri Saint-Simon (1760-1825). Para este caso, ao invés de rejeitar inteiramente o mundo à sua volta, a utopia de Saint-Simon previa uma sociedade industrial depurada de suas desordens e injustiças, sendo conduzida consensualmente pelos "produtores" - os operários, empresários, sábios, artistas e banqueiros. Em uma de suas primeiras obras, as Cartas de um habitante de Genebra a seus contemporâneos (1803), ele já havia proposto que os cientistas tomassem o lugar das autoridades religiosas na condução espiritual das sociedades modernas. Todavia, no ano de sua morte, publicaria uma obra intitulada Nova Cristandade (1825), que já se preocupava com a idéia de uma reforma religiosa ${ }^{7}$. Vale ainda lembrar que, como Fourier, Saint-Simon teve uma preocupação peculiar em discutir a necessidade de corrigir as desigualdades entre homens e mulheres, notando-se que poderemos encontrar entre os saint-simonianos algumas das mulheres pioneiras na luta pelos direitos da mulher e por uma inserção não desigual no mundo social e político. Dentre elas, é oportuno lembrar o nome de Claire Bazard (1794-1883), cofundadora da revista Femme Nouvelle, um jornal escrito exclusivamente por mulheres que teve ainda outras designações, como La Femme Libre e La Tribune dês Femmes. Além disso, com relação aos modos de distribuição da riqueza, Saint-Simon preconizava a fórmula "a cada um segundo a sua capacidade, a cada capacidade segundo o seu trabalho" (Do Sistema Industrial, 1822) ${ }^{8}$.

Um interessante modelo utópico desenvolvido literariamente, mas que também articula uma posterior tentativa de estabelecimento de comunidades utópicas nos Estados Unidos da América, é imaginado pelo socialista francês Etiènne Cabet, autor de um romance intitulado Viagem a Icária (1942). O exame atento desta construção literária - tão bem sucedida quanto a obra literária de Edward Bellamy, nosso presente objeto de estudo - requereria um artigo especial $^{9}$. Em seguida, nos dedicaremos à análise específica do modelo utópico que tomamos para objeto de estudo.

\section{A igualdade de ferro de uma utopia industrial militarizada}

Existe uma curiosa utopia, elaborada por um escritor estadunidense atuante em fins do século XIX, que imaginou literariamente uma singular proposta social que se aproxima de

\footnotetext{
${ }^{7}$ Sobre a reforma religiosa proposta por Saint-Simon, ver Desroche (1969). Para uma obra mais abrangente acerca do pensamento utópico de Saint-Simon, ver: Petre-Grenouilleau (2001) e Musso (1999).

${ }^{8}$ Saint-Simon foi, entre os socialistas utópicos, um daqueles que mais deixou seguidores no século XIX (os "saintsimonianos"), além de ter entre seus admiradores escritores românticos como Victor Hugo e George Sand (pseudônimo da escritora Amandine Aurore Lucile Dupin, baronesa de Dudevant). Entre os saint-simonianos propriamente ditos aqueles que dão continuidade a um movimento e publicam A Exposição da Doutrina de Saint-Simon - os nomes de destaque são os de Saint-Amand Bazard (1791-1832) e Barthélemy Prosper Enfantin (1796-1864). Ambos, após uma fase inicial de práticas revolucionárias entre os carbonários franceses, terminam por migrar, respectivamente em 1828 e em 1825 , para o saint-simonismo.

${ }^{9}$ Viagem a Icária - obra escrita em 1842 pelo político e escritor socialista Etiènne Cabet - despertou uma atenção igualmente notável no público francês de sua época, o que também motivou o desejo de realização de experiências utópicas. Cabet, mais tarde, comandaria uma tentativa de implantação de uma comunidade socialista nos Estados Unidos, a qual não foi bem sucedida.
} 
alguma maneira do modelo "Igualdade de Todos em Tudo", rediscutindo o papel do Estado neste modelo. Edward Bellamy (1850-1898) escreveu Olhando para trás em 1887. Mais tarde, em Igualdade (1898), o autor iria detalhar mais minuciosamente a sociedade americana deste futuro que havia previsto para o ano 2000 na sua primeira obra utópica.

Para situar o autor, devemos ressaltar que, além de ter nascido em uma pequenina cidade do estado americano de Massachusetts, provinha de uma família religiosa, tendo sido pastores batistas seu pai, sogro e um primo muito próximo ${ }^{10}$. Estudou em uma faculdade de Direito, mas a abandonou para se dedicar ao jornalismo. Depois, passou a se dedicar à literatura, escrevendo contos e novelas - atividade que culmina com a obra Olhando para Trás (1888) e com outra obra que a continua com o título Equality (1897), mas sem o arrebatador sucesso de sua predecessora. A preocupação com as injustiças sociais é visível nestas e em outras de suas obras literárias. Um ano depois da publicação de Equality, Bellamy morre prematuramente de tuberculose.

O contexto de produção de Olhando para Trás (1888), em termos simples, era o das tensões entre uma economia nacional que vinha sendo dominada por trusts e uma classe trabalhadora que já se fazia representar através de uniões trabalhistas que começavam a mobilizar, quando possível, protestos e greves por melhores salários e condições de trabalho. A América de Edward Bellamy também conhecera um período de significativa depressão entre 1873 e 1879; na própria década de 1880 - período de gestação e planejamento do romance -continuam a ocorrer recessões mais curtas. Deste modo, o autor vivencia, às vésperas da publicação de seu romance, um período de tensões sociais e de desenvolvimentos industriais marcados por inquietantes conflitos trabalhistas.

Tal como Charles Fourier fizera ao opor a sua Harmonia ao velho mundo da Civilização - nome que dava à sociedade industrial agregando-lhe uma forte carga pejorativa - Edward Bellamy também apresenta o seu universo utópico como uma verdadeira antítese do capitalismo oitocentista. As inquietações diante das desordens geradas pelos conflitos entre o Capital e o Trabalho aparecem aqui claramente. Todavia, sua indisfarçável proposta utópica reformista ainda que pareça se apoiar em elementos socialistas - não se opõe ao capitalismo à maneira dos revolucionários que pretendiam destruí-lo, mas sim apoia-se no sonho de transcendê-lo. $O$ futuro utópico de Edward Bellamy não destrói o capitalismo, mas o ultrapassa. Ao lado disso, a América bellamyniana é um espaço literário no qual seu autor discute pormenorizadamente a possibilidade de aplicação social de uma economia planificada. O ambiente retratado no livro é principalmente o urbano, o que lhe permite enfatizar um novo modelo para a civilização industrial.

Estamos aqui diante de uma obra que, ainda que hoje esteja relativamente esquecida, trouxe um significativo impacto ao mundo literário de sua época. O célebre livro escrito por Bellamy, de fato, pode ser indicado como um dos mais influentes no público leitor americano nas últimas décadas do século XIX, e este sucesso prosseguiu até pelo menos a terceira década do

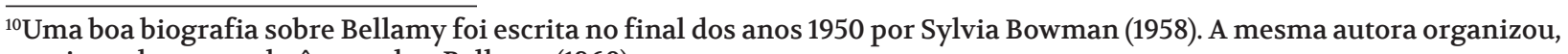
mais tarde, uma coletânea sobre Bellamy (1960). 
século $\mathrm{XX}^{11}$. As polêmicas contra o livro, na própria época de seu primeiro lançamento, também foram muitas ${ }^{12}$. Vale ainda lembrar que a utopia americana descrita em Olhando para Trás, um tanto surpreendentemente, inspirou uma significativa demanda de realizações em sua própria época e mais além. Registram-se 162 "clubes Bellamy”, já na década seguinte à publicação da obra, os quais tomaram a si a tarefa de propagar as ideias de Bellamy, ou mesmo pensar a possibilidade de sua concretização através de comunidades utópicas ${ }^{13}$. Mais tarde, no período da depressão americana dos anos 1930, a filha de Bellamy iria retomar o legado utopista do pai e reavivar a difusão dos "clubes Bellamy" nos Estados Unidos e em outros países como a Dinamarca e Alemanha, em um movimento que contou com a participação do famoso filósofo pragmatista e educador John Dewey (1859-1952).

O enredo de Olhando para Trás introduz um personagem com preocupações sociais análogas às de Bellamy, embora pertencente a um extrato social mais elevado. Julian West, o viajante do tempo nessa trama, é um abastado jovem estadunidense que, a certa altura da introdução da novela, passa a ser atormentado pela consciência de ser um dos beneficiários de um mundo repleto de injustiças sociais. Sua má [ou boa] consciência chega a dar-lhe insônias, e por isso desenvolve a prática de adormecer à noite sob efeito de hipnose, em um anexo de sua mansão situada em Boston. Sob um teto abobadado, todos os dias ele dorme o simultaneamente confortável e inquietante sono dos injustos. Certo dia, não acorda mais no tempo esperado. Dorme durante 113 anos, e só desperta no ano 2000, tendo a oportunidade de conhecer pessoalmente o futuro de seu país. O despertar de Julian West em um futuro idealizado coloca-o na típica situação prevista pelo gênero utópico: a possibilidade de comparação entre uma sociedade perfeita situada em outro plano (no caso, o futuro) e uma sociedade imperfeita a ser criticada nos seus variados aspectos ${ }^{14}$

\footnotetext{
${ }^{11} \mathrm{~A}$ influência do romance de Edward Bellamy em sua época e nas gerações subsequentes é evidenciada por um artigo da primeira metade do século XX (SADLER, 1944). O romance de Bellamy foi traduzido, na sua época, para vinte idiomas, e, em um prefácio de Eric Fromm para uma edição de 1960, este autor alemão ressalta que, à sua época, a novela de Bellamy só era superada em alcance editorial pela Cabana do Pai Tomás e por Bem-Hur(FROMM,1960, p.9). Mesmo durante a Grande Depressão, os movimentos Bellamy mantiveram-se reavivados, particularmente através da ação da viúva de Bellamy e de sua filha, as quais, para esta empresa, contaram com a já mencionada ajuda de John Dewey. De igual maneira, mesmo na quarta década do século XX identifica-se uma influência significativa do pensamento e propostas sociais de Bellamy, inclusive fora dos Estados Unidos, como demonstra a emergência em 1927 do movimento Bellamy nos Países Baixos, e em 1933 a fundação da Associação Bellamy Internacional, em Roterdan. Ainda na Holanda, em 1945 seria fundado o Partido Bellamy Neerlandês.

${ }^{12}$ Além de muitos textos e artigos de autores diversos confrontando a proposta utópica de Bellamy, a utopia Notícias de Lugar Nenhum (1890), de William Morris (1834-1896), foi em parte escrita para confrontar as idéias utópicas propostas por Edward Bellamy em Olhando para Trás. Entre os autores da época que polemizaram contra Bellamy, pode-se citar G. A. Sanders, J. A. Bachelder, R. C. Michaellis, J. W. Roberts, A. D. Vinton, entre outros. Nos anos mais recentes, em 1974, um escritor moderno de ficção científica - Mack Reynolds - reescreveu em novas cores a trama descritiva de Bellamy, denominando sua nova obra Looking Backward from the year 2000.

${ }^{13}$ De sua parte, Edward Bellamy, tal como outros idealizadores de utopias, acreditava seriamente na realização futura da sociedade que descreve em Olhando para Trás, a qual seria "uma previsão de acordo com os princípios de evolução do próximo estágio do desenvolvimento social e industrial da humanidade, especialmente neste país [Estados Unidos]" (BELLAMY, 1960, p.203).

${ }^{14}$ No enredo, o desaparecimento de West não causa maiores estranhamentos porque, coincidentemente, a mansão principal sofre um incêndio, de modo que todos terminam por acreditar que o milionário havia morrido. No anexo escondido dos olhos de todos, Julian West terá todo o tempo para descansar desacordado, com seu metabolismo preservado, até o dia de seu despertar no futuro, após um habitante futuro dos Estados Unidos descobrir seu corpo.
} 


\section{O “Nacionalismo"}

A utopia que Julian West conhecerá é uma curiosa mistura proporcionada por um desenvolvimento do capitalismo - culminante com a extinção da concorrência entre empresas - e a emergência de uma espécie de socialismo de estado, mantido por uma singular "indústria em armas" - um sistema no qual os trabalhadores vivenciam literalmente a idéia de constituir um "exército industrial"15. Em termos mais diretos, os Estados Unidos se haviam transformado em uma utopia industrial militarizada, mas não por estar em constante estado de alerta contra um inimigo externo - mesmo porque a essa altura já não existem mais guerras - e sim porque toda a estrutura de recrutamento, comando e rigor, a qual vemos habitualmente nos exércitos, voltou-se para dentro, como solução para organizar de maneira eficaz e justa a indústria e o trabalho no país ${ }^{16}$.

Nesse mundo, repleto de consumismo e dotado de algumas novidades tecnológicas, desapareceram por outro lado os desperdícios e atravessamentos (intermediações) decorrentes do sistema de competição de mercado ${ }^{17}$. Também desapareceram as crises periódicas do capitalismo. Gastos exorbitantes com propaganda? Extinguiram-se com o mercado tradicional. Ao mesmo tempo, esta quinta-essência do antigo capitalismo convergiu nitidamente para um modelo socialista de organização humana, alcançado não através de uma revolução ruidosa, ou de reformas acumuladas à esquerda através de conquistas eleitorais nos moldes da social-democracia, mas sim a partir de um aprofundamento radical do próprio capitalismo. Conforme relata um dos anfitriões de Julius West na nova era, o processo de formação de trusts (já conhecido na época de Bellamy) terminou por afunilar-se em um Grande Trust uma única grande empresa - simultaneamente à crescente associação dos trabalhadores que com o tempo evoluíram da diversidade de sindicatos para uma única grande associação laboral. O associativismo único e o Grande Trust deram-se as mãos sem qualquer comoção social, uma vez que as grandes corporações que precederam ao Grande Trust prepararam cuidadosamente a população americana para a Nova Ordem. A antiga e encarniçada luta das empresas oitocentistas pelo maior lucro possível e pelo controle do mercado, secundada por

\footnotetext{
${ }^{15}$ Bellamy evita a utilização da expressão "socialismo" para a sociedade idealizada em seu romance, e depois discutida nos "clubes Bellamy". Prefere denominar seu sistema de "nacionalismo" (BELLAMY, 1890. p.289). O nome [O Nacionalista] também reaparece no jornal editado pelo primeiro clube Bellamy, situado em Boston. Sobre o "movimento nacionalista" de Bellamy, ver o artigo de John Hope Franklin, ainda próximo à época de maior influência da novela e das obras de Edward Bellamy (FRANKLIN, 1938).

${ }^{16}$ As informações detalhadas sobre os Estados Unidos do futuro são apresentadas ao personagem da trama pelo homem que descobriu seu corpo adormecido, o Dr. Leete, e também por sua esposa e por sua filha, Edith. Serão eles os anfitriões que irão esclarecer todas as dúvidas de Julian West sobre aquela sociedade tão diferente dos Estados Unidos de fins do século XIX.

${ }^{17} \mathrm{~A}$ cadeia de atravessadores entre o produtor e o consumidor, conforme argumenta Bellamy, ampliava desnecessariamente o preço de mercadorias e constituía grande fonte de desperdícios, à qual se juntava a circulação que os consumidores tinham de fazer de loja em loja para encontrar o melhor preço entre os vendedores de um mesmo produto. Por isso, em uma cena do romance, a enamorada de Julian West mostra-lhe como funcionava agora o processo de compra de produtos pelo consumidor comum. As lojas possuíam apenas amostras únicas dos produtos produzidos pela empresa única. Escolhido um produto para ser comprado, a ordem para encomendá-lo era dada para um armazém central, e logo o produto chegaria à residência do consumidor em pouco tempo. A circulação entre lojas distintas era desnecessária, pois o preço era um só. Note-se, ainda, que Bellamy idealiza um cartão de crédito pela primeira vez.
} 
suas ambições monopolistas de fundo, deram lugar a uma economia totalmente planificada, não competitiva, capaz de harmonizar produção e consumo com vistas a assegurar a felicidade material e espiritual de cada um e de todos. Os grandes conglomerados, na trama histórica mencionada por Edward Bellamy, acabam por se mostrar, ao fim de tudo, como os grandes benfeitores da felicidade humana - bem ao contrário do que ocorreria no célebre romance 1984, de George Orwell (1903-1950), segundo o qual o mundo inteiro estaria destinado a ser finalmente repartido por três conglomerados gigantes que terminam por se transformar em governos totalitários. O pesadelo de George Orwell, de certo modo, oferece uma imagem em espelho em relação ao sonho utópico de Edward Bellamy. Em ambos tem-se uma economia totalmente planificada, a qual necessita ser alimentada por uma excitação patriótica. Os resultados, todavia, apontam respectivamente para a infelicidade e felicidade humanas ${ }^{18}$.

Bellamy nos oferece o retrato de uma curiosa economia de guerra que não deixa mortos e nem apresenta inimigos externos, ao mesmo tempo em que é vivida alegremente por cada um dos soldados-produtores que dela participam como trabalhadores e consumidores. Tem-se aqui uma intrigante sociedade militar de civis, na qual cada um sabe exatamente o seu lugar e todos desempenham as suas funções como se houvesse um grande inimigo a ser vencido diuturnamente. Um tanto ironicamente, é através de um surpreendente processo pacifista que se chega a essa utopia industrial militarizada. Admirável Gado Novo! A revolução não foi necessária, pois, sem sobressalto, tudo se reconcilia. O povo americano, a um só tempo dócil diante da preparação que lhe foi inculcada e, no entanto, determinado a tornar-se senhor de seu próprio governo e de todo o sistema industrial, é apresentado pelo anfitrião de Julian West como o grande ator da surpreendente transformação social. Tal como na Icária - uma utopia de Etiènne Cabet que foi escrita na mesma época - também aqui todos os cidadãos tornaramse funcionários públicos, trabalhadores diversificados que, na utopia de Edward Bellamy, passaram a integrar o exército industrial deste Grande Trust que passou a se confundir com o próprio Estado. O chefe maior desse exército é o presidente da república, ele mesmo só podendo ter chegado nesta posição começando de baixo, como recruta, e galgando paulatinamente um sistema à maneira das promoções militares e de acordo com um rigoroso conjunto de normas que regem a ascensão à presidência da república.

\footnotetext{
181984 foi escrito em 1948 por George Orwell (o título do livro é um anagrama do ano em que foi produzido). Neste romance, publicado em 1949 - a apenas alguns meses antes da morte do autor - o personagem principal vive em uma sociedade totalitária na qual cada indivíduo é vigiado na sua vida diária e cotidiana por teletelas que estão por toda a parte, inclusive nas residências. O governante é o Grande Irmão, ficando no ar se é mesmo um tirano real ou apenas um rosto criado e perpetuado midiaticamente. A Oceania - nome de uma vasta região do planeta que abrange a Inglaterra, as Américas e a Austrália - está sempre em guerra com um dos dois outros continentes totalitários: a Eurásia e a Lestásia. Na Oceania - e provavelmente nos dois outros continentes totalitários - a história é sempre reconstruída e recontada a partir da destruição e remontagem sistemática das fontes, documentos e memória coletiva. Parte da população é constituída de funcionários públicos, todos aprisionados por engrenagens que os obrigam a viver socialmente isolados e desconfiados uns dos outros no seio do setor urbano que os abriga. A outra parte da humanidade, muito maior, é constituída de proletários submetidos a uma vida materialmente miserável.
} 


\section{Trabalho e Ócio}

Atrás dizíamos que a utopia de Bellamy também se produz com base no modelo "De Tudo para Todos". Isso se dá através de um formato peculiar. Não apenas a riqueza é distribuída, mas também os incômodos, o trabalho menos desejável, a cota-suja. Este não é um problema pequeno. Para compreendê-lo em sua verdadeira dimensão, podemos lembrar lateralmente outra obra literária: uma curiosa distopia ${ }^{19}$, também produzida em fins do século XIX. Tratase da sociedade distópica descrita por H. G. Wells em A Máquina do Tempo. Nesta interessante obra de ficção científica escrita em 1895 pelo escritor inglês H. G. Wells (1866-1946) - a qual posteriormente recebeu duas adaptações para o cinema - o personagem principal é um cientista que constrói um aparelho capaz de transportá-lo através do tempo. Resolve ir ao futuro, e viaja até o ano 802.701. Lá, o viajante do tempo encontra uma amistosa população formada por dóceis e jovens seres humanos que vivem uma realidade que à primeira vista não parece muito distante da fantasia medieval da Cocanha ${ }^{20}$. Existem ao ar livre grandes mesas nas quais o alimento - as mais deliciosas iguarias, frutas de todos os tipos, e um saboroso menu - está eternamente à disposição dos elóis, nomes que aqueles indivíduos dão à sua própria espécie. As roupas também estão sempre disponíveis, assim como guirlandas de flores para se enfeitarem e almofadas macias para se recostarem, bem como tudo mais o que eles precisassem para terem uma aparente vida paradisíaca. Não há sinal de trabalho ${ }^{21}$. Os elóis simplesmente consomem o que está à disposição, vivendo uma vida edênica, de eterno ócio. Tampouco há indivíduos mais velhos: apenas uma eterna juventude, existindo para o prazer. Essa é a primeira impressão do "viajante do tempo".

Intrigado, ele tenta saber dos elóis como aqueles alimentos e produtos para consumo estão ali. Como eles vão parar nas grandes mesas nas quais são ofertados para que simplesmente sejam apanhados à vontade? Quem fabrica aquelas túnicas coloridas que os abrigam, os cintos que as envolvem, e as sandálias nas quais seus pés se aninham? Os elóis nada esclarecem, como ocorre também nas utopias da Cocanha [as utopias da inesgotável abundância], nas quais não se sabe quem dispôs os alimentos nas eternas mesas nas quais nada falta. Quem trabalha para que esses produtos e alimentos estejam disponíveis? Essa pergunta, feita várias vezes pelo "viajante do tempo", não tem resposta. As coisas simplesmente aparecem, simplesmente estão ali e trata-se apenas de consumi-las, respondem-lhe os elóis. Logo o viajante do tempo perceberá, todavia, que a realidade é mais sinistra. Durante a noite, ao ver uma jovem elói por quem se enamorara ser raptada por uma estranha criatura, e carregada para baixo da ${ }^{19}$ Uma distopia pode ser definida como uma "utopia negativa" (JACOBY, 2007, p.31).

${ }^{20} \mathrm{~A}$ Cocanha era uma famosa utopia medieval na qual todos os alimentos e produtos necessários à vida eram disponibilizados para os seus habitantes sem que estes precisassem trabalhar. Os rios eram metade de vinho tinto, metade de vinho branco. Os frangos passeavam pelas ruas já tostados e prontos para serem devorados. Os alimentos eram expostos à fartura em uma mesa sem fim, da qual os habitantes da Cocanha podiam se servir à vontade. O trabalho não existia. Sobre a Cocanha, ver a análise de Hilário Franco Jr (1998).

${ }^{21} \mathrm{O}$ viajante do tempo assim expressa sua primeira impressão de que o trabalho desaparecera da superfície da Terra: "Não se viam cercas nem quaisquer sinais de propriedades, ou de cultivo de cereais. Toda a Terra se tornara um único jardim" (WELLS, 1983, p.30). 
terra através de um dos poços que se espalhavam pela superfície paradisíaca do mundo, ele compreende tudo. A humanidade havia se dividido em dois grupos: os elóis, simpáticos e alienados jovens que vivem na superfície, e os morloks, seres embrutecidos que vivem debaixo da terra e produzem tudo, possuindo máquinas industriais e proporcionando aos elóis todos os alimentos necessários e um consumo irresponsável para ocupar suas insípidas vidas. Isso, contudo, tinha o seu preço: na verdade, os morloks se alimentavam dos elóis. À noite vinham sempre sequestrar alguns para serem devorados. O paraíso, portanto, era fugaz. Os elóis dificilmente passavam da faixa dos 20 anos.

Aquele - compreende o viajante do tempo - era o futuro da humanidade. Tratava-se de uma falsa Cocanha, poderíamos acrescentar, na qual, no final de tudo, o ócio e o prazer irresponsável tinham o seu preço. A abundância da superfície, disposta para a vida hedônica de belos e frágeis jovens incapazes de se defender, era contraponteada pelo trabalho subterrâneo, empreendido por homens monstruosos que os canibalizavam. Todavia, talvez mesmo estes últimos também não fossem mais do que vítimas de uma sociedade remota e de uma longa história que, em um primeiro momento, os havia explorado insanamente como trabalhadores submetidos às piores condições; e que, em outro momento, finalmente os banira para as entranhas da terra. Era esse passado de desigualdades que ali deixara seu legado, no futuro distópico imaginado por H. G. Wells. Incapazes de distribuir com igualdade o ócio e o trabalho, os seres humanos haviam sido conduzidos a separá-los em duas metades.

Voltemos agora ao nosso objeto em estudo: o modelo utópico proposto em Olhando para Trás (1888). Com relação à divisão entre ócio e trabalho, podemos dizer que na utopia americana de Edward Bellamy - escrita sete anos antes da criação distópica de H. G. Wells - um pouco de elóis e de morloks é convenientemente distribuído em partes iguais por toda a população. Como se dá isso? Vejamos como Edward Bellamy resolve o dilema de distribuir não apenas a riqueza, mas também o trabalho indesejado ou menos atrativo; e não apenas o trabalho árduo, mas também o ócio, de maneira a que não existam mais os conflitos entre uma classe dominante parasitária ou favorecida e uma classe trabalhadora encarregada de sustentar uma sociedade desigual. Para entendermos o modelo proposto por Edward Bellamy em Olhando para Trás, precisamos retomar aqui a idéia do exército industrial, fundamental nesta organização utópica.

\section{O exército industrial}

O modelo do exército industrial, aceito com espontaneidade por todos os habitantes da utopia bellamyniana, é o do recrutamento obrigatório. Ao terminar a universidade, cada jovem pé recrutado para trabalhar durante três anos sob a égide do chamado "exército laboral nãoespecializado", uma divisão do grande exército industrial que tem como missão a realização de todas as tarefas consideradas desinteressantes e mais humildes. Da coleta de lixo à atuação como garçons, as tarefas básicas são cumpridas por todos os cidadãos como parte obrigatória de sua 
trajetória nessa grande indústria militarizada. Há também, por outro lado, a possibilidade de cidadãos de outras faixas etárias assumirem as funções menos desejadas através do estímulo conferido pelo oferecimento de menos horas de trabalho. De todo modo, o salário é único absolutamente o mesmo - para todos os participantes do exército industrial. Aqui, a igualdade se apresenta de maneira rigorosa. O desaparecimento das diferenças salariais, ademais, parece ter removido concomitantemente todas as diferenças de status social. Continuemos a acompanhar a história de um indivíduo comum, pois todos os habitantes desta América imaginária, conforme logo percebe o viajante do tempo Julian West, precisam necessariamente percorrer uma mesma história de fundo. Desta maneira, a história de vida de um indivíduo qualquer se mostra como um reflexo da própria sociedade que o envolve.

Depois de cumprir seus três anos na divisão não-especializada do exército industrial, o jovem pode se inscrever como recruta em uma das divisões especializadas do exército industrial - as quais se referem aos ofícios diversificados e que podem se beneficiar de mais um circuito de educação pública para o cidadão, até os trinta anos. A mobilidade no espectro militar-industrial de postos de trabalho, ademais, é obtida através de um criterioso sistema de promoções, mas também de rebaixamentos quando não ocorre o empenho esperado. A expectativa de trabalho tem como marco a idade de quarenta e cinco anos. Com esta idade, o cidadão sai da ativa do exército industrial, mas em contrapartida transforma-se em um eleitor, que vai ter direito a votar nos candidatos a altos postos, inclusive o presidente da república. Portanto, neste sistema o indivíduo mais idoso e mais experiente é que define o governo. Há igualdade também aqui, pois, em um momento, todos foram trabalhadores ativos no exército industrial, e, em um outro, todos serão aposentados, passando à reserva do exército industrial, mas com direitos a voto e a uma integração à política eleitoral. Além disso, nessa fase, conquista-se o direito ao ócio.

Essa, com todas as suas cores, é a utopia industrial apresentada por Edward Bellamy em Olhando para Trás. Em comparação a algumas das utopias já discutidas, podemos elogiar o esforço em ultrapassar o modelo das benevolentes ditaduras de homens sábios, ou da sujeição de toda a comunidade a um único fundador-chefe do qual tudo emana, particularmente através do estabelecimento de um sistema eleitoral do qual todos participarão, no momento em que atingirem a faixa etária correspondente a este direito. A juventude, por outro lado, é excluída do processo de decisão, com conseqüências imprevisíveis. Interessante observar, ainda, que se chega historicamente a essa utopia industrial militarizada, conforme a narrativa de um dos personagens do romance, não através de uma revolução, mas de um surpreendente consenso. E, mais uma vez, a transformação é encaminhada pelos representantes mais elevados da hierarquia de industriais.

Podemos acrescentar um comentário sobre a crença de Edward Bellamy em uma natureza humana cooperativa e não egoísta, apesar de sua contumaz crítica à desigualdade de sua época. Essa bondade natural do homem, parece-nos dizer Bellamy, não pode senão aflorar naturalmente quando lhe damos o sistema correto, o mais eficiente, o que permite a verdadeira justiça social. Neste futuro proposto pela utopia de Bellamy, o individualismo típico da sociedade 
industrial oitocentista foi totalmente substituído pela cooperação; a rede de negócios privados foi substituída pela Empresa-Estado única, alimentada permanentemente pela contribuição coletiva ao Bem Comum. Os crimes desaparecem, assim como o desejo de lucrar ou explorar o próximo.

\section{Honra e Prestígio}

Em mais um traço igualmente relacionado a este curioso estado de guerra sem inimigos e em plena paz, paira no ar, sobre tudo e todos, um irresistível desejo patriótico de servir ao Estado Industrial Militarizado e ao bem comum. A excitação patriótica que no mundo conhecido até o século XIX se inflamava nos períodos belicosos, e que permitia aos homens mergulharem momentaneamente na insanidade da guerra de uns contra os outros, agora parece ter se transformado em uma excitação patriótica endêmica. A guerra se naturalizou, faz parte da natureza humana expressa em cada indivíduo do futuro utópico proposto por Bellamy; mas não é mais propriamente uma guerra, e sim uma psico-economia de guerra em um mundo em paz - ou uma excitação guerreira vivida pacificamente. Essa estranha guerra sem inimigos não tem mais nenhum resíduo do ancestral caráter destrutivo das guerras tradicionais. A guerra em paz, racionalizada, volta agora todas as energias para a construção, através do trabalho, daquilo que será consumido por todos em um regime de rigorosa e estrita igualdade. Por isso mesmo, trata-se de uma guerra sem economia de guerra, uma vez que a eficiência do sistema produz a abundância, no mesmo passo em que o seu igualitarismo permite que essa abundância seja repartida com equanimidade por todos.

É, aliás, todo um sistema de virtudes guerreiras, mas agora filtradas da destrutividade da guerra, o que parece conformar a psicologia ideal e a moral preconizada para cada cidadão da nova ordem. O orgulho de pertencer à nação e servi-la como um dedicado soldado-trabalhador, a honra e as distinções dela provenientes, a devoção à comunidade e ao bem comum, eis aqui as virtudes que são cultivadas desde a educação infantil, e que continuam a ser estimuladas na vida adulta. A competitividade ficou para trás, e, quando muito, expressa-se na busca de maior eficiência e produção a ser retribuída ao Estado. Os prêmios e medalhas, as distinções e ranqueeamentos - moedas simbólicas que constituem também uma das bases de satisfação neste novo mundo - coroam o trabalho produzido, e não mais as façanhas bélicas ou uma lista de inimigos derrotados. Se são moedas simbólicas, contudo, não afetam de sua contraparte a capacidade de consumo, que para todos é a mesma. Cada setor ou divisão industrial possui os seus próprios emblemas e distintivos, e criam novos modelos de pertencimento, sem afetar o sentimento maior de pertença ao país. O orgulho de pertencer ao exército de trabalhadores, enfim, é análogo ao antigo orgulho de um soldado em pertencer a uma divisão militar destacada ou a uma legião. Amar a pátria é amar este sistema do qual o indivíduo se converteu em uma alegre engrenagem, ou em uma pequena abelha que tem o direito à produção e ao consumo do mesmo mel. 


\section{O lugar do Artista}

Neste mundo de alegres abelhas, há também lugar para as cigarras, desde que o seu canto seja acompanhado do devido reconhecimento social e valorizado pelo conjunto dos trabalhadores. Um curioso sistema de exceção permite que artistas, autores e inventores - e também os professores, pontuados nesta mesma categoria excepcional - possam se dedicar a oferecer para a comunidade o sutil produto derivado de seus talentos e habilidades específicas. As distinções para a classe criativa fundam-se em um modelo paralelo: as fitas vermelhas demarcam os mais bem sucedidos. $O$ trabalho criativo pode compor com o trabalho comum a contribuição de um indivíduo criador à sociedade, já que este pode ser dispensado de horas de trabalho conforme o que realmente produza em sua área de excelência, desde que haja um reconhecimento social efetivo que ateste objetivamente a sua contribuição à comunidade.

Um literato, por exemplo, pode ser dispensado de horas de trabalho com base na renovação de seus direitos autorais. O Estado, aliás, é o único editor, tanto para livros produzidos por cidadãos como para os jornais, em um sistema que garante a publicação de obras, sem qualquer forma de censura estatal, desde os leitores de um livro confirmem com o seu próprio consumo a validade da obra. Assim um autor é livre para especificar, em relação a uma obra que produziu, a sua porcentagem de direitos autorais, e dela poderá viver enquanto puder, na medida em que ela seja efetivamente adquirida pelos cidadãos-trabalhadores. Um autor, deste modo, será sempre dependente dos seus leitores. A cigarra precisa ser acolhida pelas formigas. Canta, enquanto houver ouvidos que a apreciem.

A fundação de um jornal também percorre trâmites similares, já que o jornalista empreendedor precisa convencer cidadãos comuns a abrirem mão de parte de seus rendimentos fixos para que o primeiro número da publicação seja concretizado e para que continue a ser consumido nos números seguintes. $\mathrm{O}$ trabalho do jornalista também deve ser deduzido do mesmo processo, permitindo que ele substitua por este tipo de trabalho a atuação regular à qual estaria obrigado habitualmente, nas fileiras do exército industrial. De modo geral, podese dizer que o artista, o escritor, o inventor, ou qualquer outro tipo de trabalhador criativo, deve encontrar junto à população consumidora uma maneira de indenizar, ao país, a sua ausência no sistema de trabalho comum. Ou, visto ainda de outro modo, o sistema permite que o cidadão-artista indenize o exército industrial com produção criativa, a qual deve ser reconhecida socialmente, de modo a compensar a sua não-participação na "guerra" diária da produção. 


\section{Considerações finais}

O mundo de Olhando para Trás, conforme pudemos ver, atualiza problemas concretos da sociedade que o ajudou a ser imaginado, através da criação literária de Edward Bellamy. Os trustes que principiavam a se formar, e as associações de trabalhadores que começavam a despontar em fins do século XIX, bem como a necessidade de equacionar trabalho e ócio, ou destensionar as relações entre Trabalho e Capital, são problemas e questões reais que ocupam o seu lugar no romance. De igual maneira, a utopia imaginada dá expressão à ânsia de atingir um modelo igualitarista de produção e consumo, acompanhando a resposta 'número quatro' prevista no esquema sugerido em um dos itens iniciais deste artigo ("Um pouco de tudo para todos").

A solução através do Estado e da economia totalmente planificada - mas que, no fim das contas, termina por funcionar como um mecanismo bem ajustado e que se reproduz diuturnamente - também dialoga com outras utopias que procuraram trabalhar a mesma resposta desde o século XVI. Em contrapartida, os sábios ou o grupo que toma a si a tarefa de organizar e repensar o sistema - ao contrário de utopias como a da República platônica ou as utopias que seguem o modelo da Utopia de Thomas Morus - não constituem uma classe ou elite diferenciada. Os cidadãos que constituem o governo, incluindo o presidente - assimilado a um general que comanda pacificamente o seu exército - emergem da população de trabalhadores comuns. O problema do artista, ou, mais propriamente, da sustentação do artista, também é contemplado ao nível de exceção ou brecha autorizada no sistema.

A obra, além disso, antecipa o futuro em pelo menos uma conquista tecnológica importante: o cartão de crédito. Ao invés de pontuar desigualdades sociais, contudo, o cartão de crédito seria símbolo da igualdade. O dinheiro, nesse caso, deixaria de circular majoritariamente na sua forma moeda, e as mercadorias - a preço único para cada produto - poderiam ser adquiridas instantaneamente pelos consumidores, todos beneficiados pelo mesmo poder aquisitivo. Ao lado disto, o respeito às demandas de cada consumidor também é contemplado, uma vez que diferentes cidadãos poderiam consumir - com o mesmo potencial aquisitivo - diferentes combinações de bens e serviços. A tradicional contradição capitalista entre uma produção coletiva e uma distribuição socialmente desigual desaparece sem eliminar a diversidade de interesses e o direito de fazer escolhas relacionadas ao consumo.

O sucesso literário do romance Olhando para Trás foi surpreendente em sua própria época. Por outro lado, Edward Bellamy, como idealizador utópico que tenta passar à prática com a fundação dos "clubes Bellamy”, não consegue mais sucesso do que Charles Fourier, eternamente à espera do capitalista que se interessasse em financiar o seu projeto utópico, e seus seguidores não conseguem mais sucesso do que Etiènne Cabet (1842), autor que, após publicar com grande sucesso o romance utópico Viagem a Icária, fracassa nas tentativas de fundar pequenas comunidades utópicas nos Estados Unidos da América. Enquanto isso, o romance de Edward 
Bellamy prosseguiu como um dos mais influentes livros americanos até a terceira década do século XX. Examinar que circunstâncias e novos contextos históricos teriam sinalizado para o declínio de seu quantitativo leitor - a partir da crise americana de 1929 e da emergência de movimentos fascistas na Europa, ao mesmo tempo em que se assistia à primeira experiência de socialismo real, conduzida pela União Soviética a partir de 1917 - seria uma interessante agenda para pesquisas futuras.

\section{REFER $\hat{E N C I A S}$}

BACON, Francis. A Nova Atlântida. São Paulo: Abril Cultural, 1980. (Os Pensadores) Original de 1610 .

BELLAMY, Edward. Daqui a cem anos: revendo o futuro. Rio de Janeiro: Record, 1960. Original de 1888 .

BELLAMY, Edward. Equality. New York: D. Appleton \& Company, 1898.

BELLAMY, Edward. What 'Nationalism' Means. The Eclectic Magazine of Foreign Literature (18441898). v.52, n.3, p.289-ss. Sep., 1890.

BOBBIO, Norberto. Teoria Geral da Política - a filosofia política e as lições dos clássicos. Rio de Janeiro: Campus, 2000. Original de 1999.

BOWMAN, Sylvia E. The Year 2000: a critical biography of Edward Bellamy. New York: Bookman Associates, 1958.

BUONARROTI, Philippe. Babeuf's conspiracy for equality. London: Hetherington, 1836.

CABET, Etienne. Voyage on Icarie. Paris: Au Bureau du Populaire, 1842.

CAMPANELla, T. Cidade do Sol. São Paulo: Abril Cultural,1980. Original de 1602.(Os Pensadores).

CIORANESCU, Alexandre. L'avenir du passe - utopie et littérature. Paris: Gallimard, 1972.

DESROCHE, H. Saint-Simon. Le nouveau christianisme et les Écrits sur la religion. Paris: Seuil, 1969.

FIRPO, Luigi. Por uma definição da "Utopia". Tradução de Carfos Eduardo o. Berriel. Morus: Utopia e Renascimento, Campinas, n. 2, p.227-237, 2005.

FRANKLIN, John Hope. Edward Bellamy and the Nationalist Movement. The New England Quarterly, Boston, v. 11, p.739-772, dec., 1938. 
FROMM, Erich. Prologue. In: BELLAMY, E. Looking Backward 2000-1887. New York: Signet, 1960.

FUNKE, Hans Gunter. L'évolution semantique de La notion d'Utopie en français" In: HUDDE, Heinrich; KUON, Peter (Eds.). De l'utopie a l'uchronie. Tubingen: G Narr, 1988. p. 19-37.

JACOBY, Russell. Imagem Imperfeita: Pensamento Utópico para uma Época Antiutópica. Rio de Janeiro: Civilização Brasileira, 2007.

LEVITAS, Ruth. The Concept of Utopia. Syracuse: Syracuse University Press, 1990.

MORRIS, Williams. Notes from Nowhere. New York: Oxford University Press, 2003. Original de 1890.

MORUS, Thomas. Utopia. São Paulo: Abril Cultural, 1980. Original de 1516. (Os Pensadores).

MUSSO, Pierre. Saint Simon et les saint-simoniisme. Paris: PUF, 1999.

NEUSÜSS, A (Ed.). Utopia. Barcelona: Barral, 1971.

ORWELL, George. 1984. São Paulo: Companhia das Letras, 2000.

PETRE-GRENOUILLEAU, Olivier. Saint-Simon, l'utopie ou la raison en actes. Paris: Payot, 2001.

PLATÃO. A República. Lisboa: Fundação Calouste Gulbenkian, 1993. Original: cerca de 380 a.C.

QUARTA, Cosimo. Utopia: gênese de uma palavra-chave. Morus: Utopia e Renascimento, Campinas, n. 3, p.35-53, 2006.

RACAULT, Jean-Michel. Da ideia de perfeição como elemento definidor da utopia: as utopias clássicas e a natureza humana. Morus: Utopia e Renascimento, Campinas, n. 6, p.29-45, 2009.

REYNOLDS, Mack. Looking Backward from the Year 2000. New York: Ace Books, 1974.

SADLER, Elizabeth. One Book's Influence: Edward Bellamy's Looking Backward. The New England Quarterly, Boston, v. 17, p.530-555, dec., 1944.

SAINT-SIMON, C-H. New Christianity.Original de 1825. Disponível em: <http://la.utexas.edu/ users/hcleaver/368/368StSimon6NewChristianity.pdf>. Acesso em: 10 set. 2016.

SAINT-SIMON, Claude Henri de Rouvroy. Letres d'un habitant de Genève à ses contemporains. Paris: Alcan, 1925. Original de 1803.

SEN, Amartya K. Desigualdade reexaminada. Rio de Janeiro: Record, 2001. Original de 1992. 


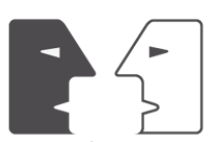

ANTÍTESES

SUVIN, Darko. Pour une définition de l'utopie comme genre littéraire. In: Pour une poétique de la science-fiction. Études en theorie et en histoire d'un genre littéraire. Montréal: Les Presses de l'Université du Quebec, 1977. p.47-69.

WELLS, H. G. A Máquina do Tempo. Rio de Janeiro: Francisco Alves, 1983. Original de 1895. 